Abstracta Iranica Abstracta Iranica

Revue bibliographique pour le domaine irano-aryen

Volume 28 | 2007

Comptes rendus des publications de 2005

\title{
Ethics of Management and Situational Leadership in Afghanistan. Aglob publishers, 2005, 243 p.
}

\section{Anicée Van Engeland}

\section{(2) OpenEdition}

1 Journals

Édition électronique

URL : http://journals.openedition.org/abstractairanica/19961

DOI : 10.4000/abstractairanica. 19961

ISSN : 1961-960X

\section{Éditeur :}

CNRS (UMR 7528 Mondes iraniens et indiens), Éditions de l'IFRI

\section{Édition imprimée}

Date de publication : 15 mai 2007

ISSN : 0240-8910

\section{Référence électronique}

Anicée Van Engeland, « Ethics of Management and Situational Leadership in Afghanistan. Aglob publishers, 2005, 243 p. », Abstracta Iranica [En ligne], Volume 28 | 2007, document 469, mis en ligne le 18 septembre 2007, consulté le 25 septembre 2020. URL : http://journals.openedition.org/ abstractairanica/19961 ; DOI : https://doi.org/10.4000/abstractairanica.19961

Ce document a été généré automatiquement le 25 septembre 2020.

Tous droits réservés 


\title{
Ethics of Management and Situational Leadership in Afghanistan. Aglob publishers, 2005, $243 \mathrm{p}$.
}

\author{
Anicée Van Engeland
}

Ce livre apporte une réflexion sur l'histoire politique de l'Afghanistan et donne de solides références en matière d'évolution de la société afghane. L'A. aborde les problématiques liées à une économie renaissante. Il décrit la situation de l'emploi en Afghanistan et les problèmes éthiques liés au travail et présente aussi les nouveaux standards éthiques, économiques et commerciaux qui se mettent en place ainsi que de nouvelles règles de travail. L'A. analyse ensuite les attentes de la société, les notions nouvelles d'éthique sociale et il évoque aussi les conflits ethniques et culturels qui transcendent le milieu du travail. Il se concentre ensuite sur les besoins économiques du pays et de ses habitants et explique comment les Afghans s'adaptent aux structures économiques modernes et s'ajustent aux notions de management. L'A. analyse donc les nouvelles conditions de travail, la nouvelle économie et le rôle de la société dans cette économie.

\section{INDEX}

Thèmes : 13.2. Afghanistan 